\title{
Increase in thermal stability of proteins adsorbed on biomass charcoal powder prepared from plant biomass wastes
}

\author{
Hidetaka Noritomi ${ }^{1}$, Ryotaro Kai ${ }^{1}$, Daiki Iwai ${ }^{1}$, Hirotaka Tanaka ${ }^{1}$, Reo Kamiya ${ }^{1}$, Masahiko Tanaka ${ }^{2}$, \\ Kohichiroh Muneki ${ }^{3}$, Satoru Kato ${ }^{1}$ \\ ${ }^{1}$ Department of Applied Chemistry, Tokyo Metropolitan University, Minami-Ohsawa, Hachioji, Tokyo, Japan;
${ }^{2}$ EEN Co., Ltd., 2-1-2 Koishikawa Bunkyo-ku, Tokyo, Japan;
${ }^{3}$ Industry-Academic-Public Cooperation Center, Tokyo Metropolitan University, Minami-Ohsawa, Hachioji, Tokyo, Japan.
Email: noritomi@tmu.ac.jp
}

Received 2 August 2011; 6 September 2011; accepted 9 October 2011.

\begin{abstract}
Thermal stability of lysozyme adsorbed on biomass charcoal powder (BCP), which was prepared from plant biomass wastes such as dumped adzuki bean, bamboo, and wood by pyrolysis without combustion under nitrogen atmosphere and comminution with a jet mill, was examined. Adsorbing lysozyme on BCP could sufficiently prevent proteins from denaturing and aggregating in an aqueous solution at high temperatures, and enhanced the refolding of thermally denatured proteins by cooling treatment. The remaining activities of lysozyme adsorbed on BCP of adzuki bean exhibited $51 \%$ by cooling treatment after the heat treatment at $90^{\circ} \mathrm{C}$ for $30 \mathrm{~min}$, although that of native lysozyme was almost lost under the same experimental conditions. The thermostabilization effect of BCP on the remaining activity of adsorbed lysozyme was markedly dependent upon the kind of plant biomass wastes.
\end{abstract}

Keywords: Adsorption; Biomass Charcoal Powder; Lysozyme; Refolding; Remaining Activity; Thermal Stability

\section{INTRODUCTION}

Proteins are biomolecules of great importance in the medical, pharmaceutical, and food fields, since they exhibit their outstanding biological activities under mild condition. However, most of proteins dissolved in an aqueous solution are immediately denatured and inactivated at high temperatures due to the disruption of weak interactions, including ionic bonds, hydrogen bonds, and hydrophobic interactions, which are prime determinants of protein tertiary structures $[1,2]$. In particular, protein aggregation easily occurs upon the exposure of the hydrophobic surfaces of a denatured protein, and this phe- nomenon becomes the major problem because of the irreversible inactivation. Thermal denaturation of proteins is a serious problem not only in the separation and storage of proteins but also in the processes of biotransformation, biosensing, drug production, and food manufacturing. Several strategies have so far been proposed in order to prevent thermal denaturation of proteins. They include chemical modification, immobilization, genetic modification, and addition of stabilizing agents. The addition of stabilizing agents is one of the most convenient methods for minimizing thermal denaturation [3-11]. It has been reported that inorganic salts, polyols, sugars, amino acids, amino acid derivatives, chaotropic reagents, and water-miscible organic solvents are available for improving protein stability. However, these additives do not sufficiently prevent irreversible protein aggregation or some of them are no longer stable at high temperatures. We have reported that adding water-miscible aprotic ionic liquids into an aqueous solution of proteins can effectively hinder the formation of protein aggregation at high temperatures, and keep high remaining activities of proteins [12]. At present, ionic liquids are at high costs, and their use is limited, since ionic liquids are organic salts. On the other hand, immobilization of proteins on a support noncovalently and covalently has extensively been studied $[13,14]$. Enzymes immobilized within carbon paste electrodes exhibit the improvement of thermal stability [15]. Enzymes enhance thermal stability by adsorbing them onto $\mathrm{C}_{60}$ fullerenes [16]. In order to develop the practical process, the factors such as the cost of the process, the need for a specific support material, ensuring that the substrates are not sterically hindered from diffusing to active site of the immobilized enzyme where they react at a suitable rate, and so on must be taken into account [17].

The development of technologies for recycling wastes is one of the most important challenges to establish re- 
cycling society. Wastes are carbonized to be applied to soil modifiers and humidity materials, and, moreover, activated carbons are produced from raw materials containing rich carbon [18-22]. In the present work, the finely grinded biomass charcoal powder (BCP) was prepared from plant biomass wastes such as dumped adzuki bean, bamboo, and wood by pyrolysis without combustion under nitrogen atmosphere and comminution with a jet mill. The characteristics of the production process of BCP in the present work are as follows: First, as plant biomass wastes are not burned in the production process of BCP, carbon dioxide emissions are reduced, and the atom economy of carbon is high. Second, as the production process of $\mathrm{BCP}$ is carried out at low temperatures compared to the conventional production process of charcoal, the energy cost is held down. Thus, BCP is obtained by environmentally benign process, is at low costs, and has no toxicity. We have focused on the remaining activity of proteins after heat treatment in order to address a question of whether or not adsorbing proteins on BCP affects the thermal stability of proteins in aqueous solutions. As a model protein, chicken eggwhite lysozyme has been employed, since it is well investigated regarding its structure, properties, functions, and thermal stability [23-25].

\section{EXPERIMENTAL}

\subsection{Materials}

Lysozyme from chicken egg while (EC 3.2.1.17, 46400 units/mg solid, MW $=14,300, \mathrm{pI}=11.1$ ) and Micrococcus lysodeikticus (ATCC No. 4698) were purchased from Sigma-Aldrich Co. (St. Louis, USA).

\subsection{Preparation of Biomass Charcoal Powder}

The process of preparing biomass charcoal powder (BCP) from adzuki bean is shown in Figure 1. Under nitrogen atmosphere, adzuki bean was dried at $180^{\circ} \mathrm{C}$ for $2 \mathrm{hr}$, was pyrolyzed at $450^{\circ} \mathrm{C}$ for $2 \mathrm{hr}$, was carbonized at $350^{\circ} \mathrm{C}$ for $3 \mathrm{hr}$, and was cooled at $100^{\circ} \mathrm{C}$ for $1 \mathrm{hr}$ by pyrolyzer (EE21 Pyrolyzer, EEN Co. Ltd., Japan). Biomass charcoal powder (BCP) was obtained by grinding the resultant biomass charcoal (BC) with jet mill (100AS, Fuji Sangyo Co. Ltd., Japan). BCP of bamboo or wood was prepared by the same method.

\subsection{Preparation of Lysozyme Adsorbed on Biomass Charcoal Powder}

In order to adsorb lysozyme on BCP of adzuki bean, $0.01 \mathrm{M}$ phosphate buffer solution at $\mathrm{pH} 7$ containing 500 $\mu \mathrm{M}$ lysozyme and $3 \mathrm{~g} / \mathrm{L}$ BCP of adzuki bean was incubated at $25^{\circ} \mathrm{C}$ and $120 \mathrm{rpm}$ for $24 \mathrm{hr}$. After adsorption, lysozyme adsorbed on BCP was recovered by filtrating the mixture with a membrane filter. The amount of lysozyme adsorbed on BCP was calculated by subtracting the amount of lysozyme included in the supernatant liquid after adsorption from the amount of lysozyme in its aqueous solution before adsorption. The amount of lysozyme was measured by UV absorption at $280 \mathrm{~nm}$.

\subsection{Heat Treatment of Lysozyme Adsorbed on Biomass Charcoal Powder}

A requisite amount of lysozyme adsorbed on $\mathrm{BCP}$ was dispersed in $0.01 \mathrm{M}$ phosphate buffer solution at $\mathrm{pH} 7.0$, and then the mixture was incubated in thermostated silicone oil bath at $90^{\circ} \mathrm{C}$ for $30 \mathrm{~min}$.

\subsection{Measurement of Remaining Activity of Lysozyme}

Lysozyme catalyzes hydrolysis of the $\beta-1,4$ glycosidic linkage between the $N$-acetylmuramic acid and $N$-ace-

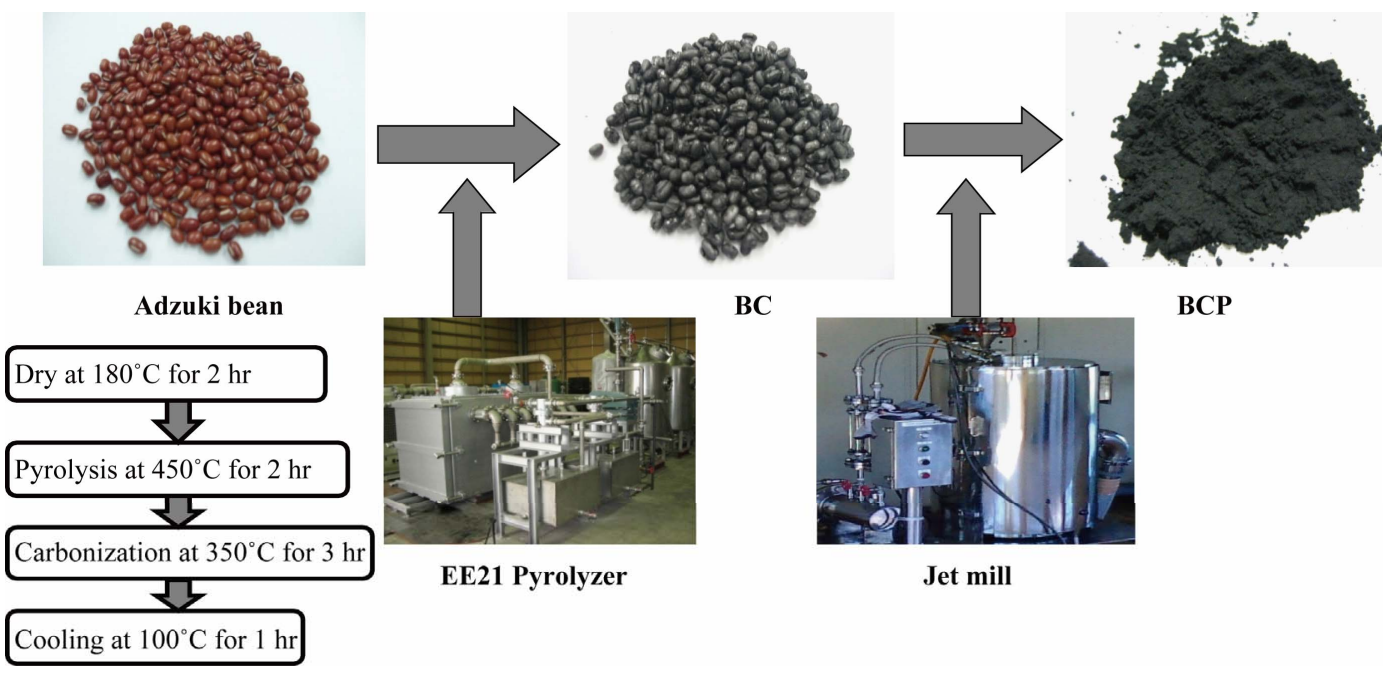

Figure 1. Process of preparation of biomass charcoal powder derived from adzuki bean. 
tylglucosamine components of peptidoglycan. This causes breakdown and removal of peptidoglycan from the bacterium which results in cell bursting or lysis in natural hypotonic solutions [13]. After the heat treatment, an aqueous solution of lysozyme adsorbed on BCP was cooled in thermostated water bath at $25^{\circ} \mathrm{C}$ for $30 \mathrm{~min}$. After $350 \mu \mathrm{L}$ of the cooled aqueous solution of lysozyme adsorbed on BCP was added to $21 \mathrm{~mL}$ of $0.01 \mathrm{M}$ phosphate buffer solution at $\mathrm{pH} 7$ containing $200 \mathrm{mg} / \mathrm{L}$ Micrococcus lysodeikticus, and then the mixture was incubated by stirring at $25^{\circ} \mathrm{C}$, the absorbance of the mixuture was periodically measured at $450 \mathrm{~nm}$ by UV/ vis spectrophotometer (UV-1800, Shimadzu Co. Ltd.). Bacterial lysis obeys a first order reaction. The lysis rate constant $(k)$ is calculated by

$$
\ln \left(A_{450}^{o} / A_{450}\right)=k t
$$

where $t, A_{450}^{o}$, and $A_{450}$ are the reaction time, the absorbance of the substrate solution at $450 \mathrm{~nm}$ at $\mathrm{T}=0$, and the absorbance of the substrate solution at $450 \mathrm{~nm}$ at $\mathrm{T}=t$, respectively. The remaining activity (R.A.) is defined as

$$
R . A .=100 \times k / k_{o}
$$

where $k_{o}$ and $k$ are the lysis rate constants at $25^{\circ} \mathrm{C}$ of lysozyme adsorbed on BCP before and after heat treatment, respectively.

\section{RESULTS AND DISCUSSION}

\subsection{Thermal Inactivation of Lysozyme}

Modest heating causes proteins dissolved in an aqueous solution to be denatured and inactivated by unfolding of proteins due to the disruption of weak interactions such as ionic bonds, hydrogen bonds, and hydrophobic interactions, which are prime determinants of protein tertiary structures as seen in Figure 2 [1,2,12,26,27]. Moreover, the intermolecular aggregation among unfolded proteins, the incorrect structure formation, and the chemical deterioration reactions in unfolded proteins proceed. In particular, protein aggregation easily occurs upon the exposure of the hydrophobic surfaces of a protein, and this phenomenon becomes the major problem because of the irreversible inactivation. On the other hand, when a heated solution of denatured proteins without protein aggregation is slowly cooled back to its normal biological temperature, the reverse process, which is renaturation with restoration of protein function, often occurs. Accordingly, if proteins are steadily adsorbed on BCP, and the aggregation among unfolded proteins adsorbed on BCP is sufficiently hindered, it is then expected that unfolded proteins adsorbed on BCP are refolded by cooling treatment, and the high remaining activity is obtained.

Lysozyme adsorbed on BCP of adzuki bean prepared

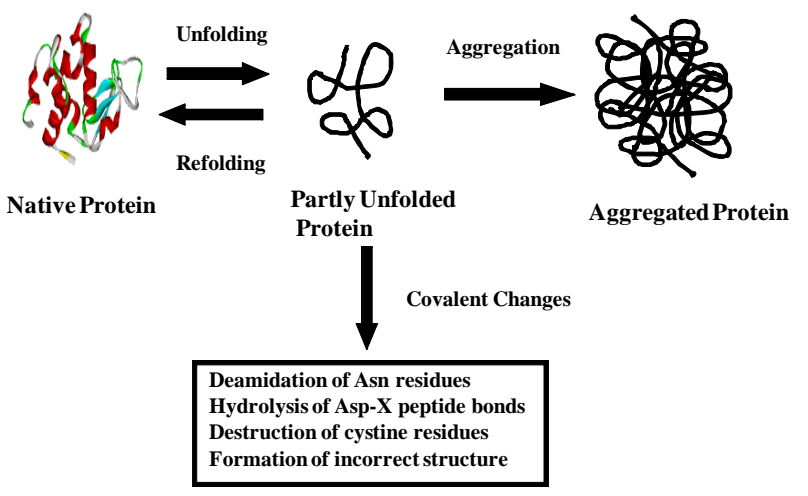

Figure 2. Schematic representation of thermal denaturation of proteins.

in the present work had its characteristics as follows. The mean diameter of BCP of adzuki bean was $7 \mu \mathrm{m}$. Amount of lysozyme adsorbed on BCP of adzuki bean was $11 \mu \mathrm{mol} / \mathrm{g}(0.16 \mathrm{~g} / \mathrm{g})$. As overall BCP concentration was $3 \mathrm{~g} / \mathrm{L}$ in an aqueous solution, overall lysozyme concentration in the aqueous solution corresponded to 33 $\mu \mathrm{M}(0.47 \mathrm{mg} / \mathrm{mL})$. The effectiveness factor, which was defined as the ratio of the lysis rate constant of lysozyme adsorbed on BCP of adzuki bean to that of native lysozyme, exhibited 0.55 .

Figure 3 shows photographs of aqueous solutions containing native lysozyme, the mixture of lysozyme and BCP of adzuki bean, and lysozyme adsorbed on BCP of adzuki bean before and after heat treatment was carried out at $90^{\circ} \mathrm{C}$ for $30 \mathrm{~min}$ as an accelerated test. Native lysozyme solution immediately became turbid due to the formation of protein aggregation, as soon as heat treatment was carried out, as shown in Figure 3(d). It has been reported that the precipitation due to protein aggregation is observed above $10 \mu \mathrm{M}$ lysozyme [25]. As lysozyme concentration in the present work was $33 \mu \mathrm{M}$ which was three times higher than that, the formation of protein aggregation was enhanced. BCP of adzuki bean spontaneously dispersed in an aqueous solution by adding BCP of adzuki bean into an aqueous solution, since BCP of adzuki bean had good wettability to water as seen in Figure 3(b). When the mixture of lysozyme and BCP of adzuki bean was prepared by adding BCP of adzuki bean into lysozyme solution, and heat treatment was immediately carried out, the precipitation consisting of denatured proteins and BCP of adzuki bean was observed due to the aggregation of free denatured proteins, as shown in Figure 3(e). Lysozyme adsorbed on BCP of adzuki bean easily dispersed in an aqueous solution by adding lysozyme adsorbed on BCP of adzuki bean into an aqueous solution, as seen in Figure 3(c). After the heat treatment of the solution of lysozyme adsorbed on BCP of adzuki bean, the state of dispersion of lysozyme 
adsorbed on BCP of adzuki bean in the solution was similar to that before heat treatment, and any aggregation was not observed in the solution, as shown in Figure 3(f). Figure 4 shows the remaining activities of native lysozyme, the mixture of lysozyme and BCP of adzuki bean, and lysozyme adsorbed on BCP of adzuki bean after heat treatment at $90^{\circ} \mathrm{C}$ for $30 \mathrm{~min}$. Native lysozyme almost lost its activity after heat treatment. The remaining activity in the mixture of lysozyme and $\mathrm{BCP}$ of adzuki bean exhibited $2 \%$. On the other hand, the remaining activity in lysozyme adsorbed on BCP of adzuki bean showed $51 \%$.

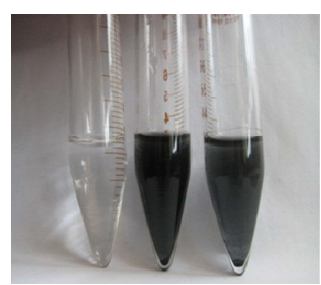

(a) (b) (c)

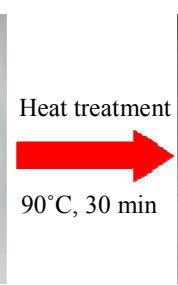

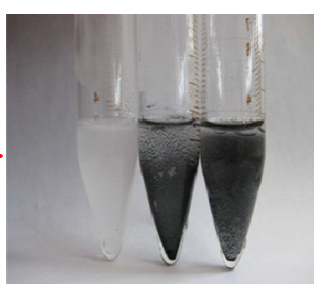

(d) (e) (f)
Figure 3. Photographs of lysozyme solutions before and after heat treatment at $90^{\circ} \mathrm{C}$ for $30 \mathrm{~min}$ : (a) an aqueous solution containing native lysozyme before heat treatment; (b) an aqueous solution containing native lysozyme solution and BCP of adzuki bean before heat treatment; (c) an aqueous solution containing lysozyme adsorbed on BCP of adzuki bean before heat treatment; (d) an aqueous solution containing native lysozyme after heat treatment; (e) an aqueous solution containing native lysozyme solution and BCP of adzuki bean after heat treatment; (f) an aqueous solution containing lysozyme adsorbed on BCP of adzuki bean after heat treatment. Overall concentrations of lysozyme and BCP were $33 \mu \mathrm{M}$ and $3 \mathrm{~g} / \mathrm{L}$, respectively.

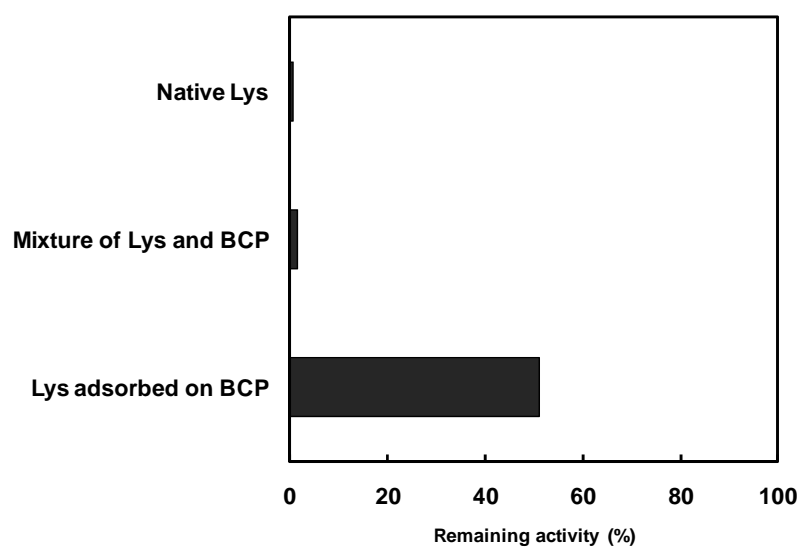

Figure 4. Effect of preparation mode on remaining activity after heat treatment at $90^{\circ} \mathrm{C}$ for $30 \mathrm{~min}$ : Native Lys, native lysozyme; Mixture of Lys and BCP, the mixture of native lysozyme solution and BCP of adzuki bean; Lys adsorbed on $\mathrm{BCP}$, lysozyme adsorbed on BCP of adzuki bean. Overall concentrations of lysozyme and BCP were $33 \mu \mathrm{M}$ and $3 \mathrm{~g} / \mathrm{L}$, respectively.

\subsection{Refolding of Lysozyme Adsorbed on Biomass Charcoal Powder}

Figure 5 shows the time course of remaining activity in lysozyme adsorbed on BCP of adzuki bean at $25^{\circ} \mathrm{C}$ after the heat treatment at $90^{\circ} \mathrm{C}$ for $30 \mathrm{~min}$. The remaining activity of lysozyme adsorbed on BCP of adzuki bean exhibited $30 \%$ just after heat treatment, increased with incubation time, and reached a plateau at $30 \mathrm{~min}$, respectively. Immobilization of proteins improves thermal stability of proteins by the rigidity of protein molecules due to the interaction of protein molecules with supports $[1$, $2,13]$. In thermal denaturation of lysozyme without protein aggregation, when the hydrophobic core of proteins is exposed, but the disulfide bonds keep intact, denatured proteins gradually refold to their native structures on cooling after thermal denaturation [28-32]. In the present system, it was suggested that adsorbing proteins on BCP hindered aggregation of thermally denatured proteins, caused some of proteins to be intact at high temperatures, and enhanced the refolding of thermally denatured proteins by cooling treatment, as seen in Figure 6.

\subsection{Dependence of the Remaining Activity of Lysozyme Adsorbed on Biomass Charcoal Powder on the Temperature of Heat Treatment}

Figure 7 shows the relationship between the temperature of heat treatment and the remaining activity of lysozyme adsorbed on BCP of adzuki bean after the heat treatment for $30 \mathrm{~min}$. As seen in the figure, the dependence of the remaining activity on the temperature exhibited the sigmoid curve. The remaining activity of native lysozyme dramatically decreased with an increase in temperature in the range from $60^{\circ} \mathrm{C}$ to $90^{\circ} \mathrm{C}$, and was then lost at

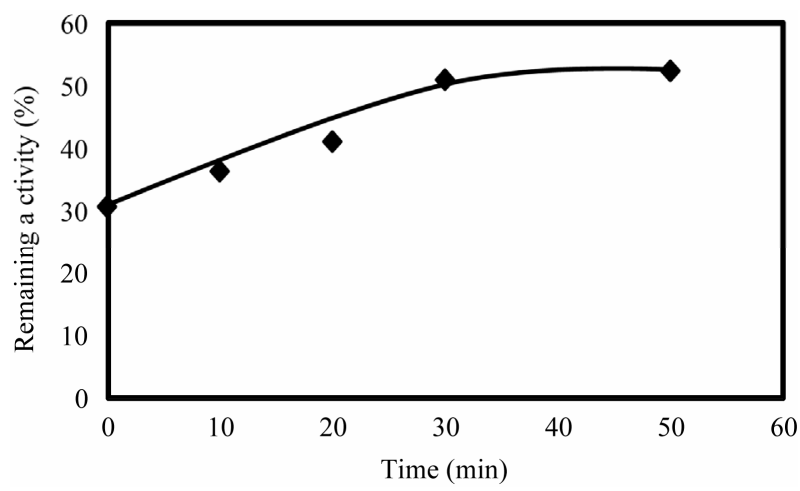

Figure 5. Time dependence of remaining activity of lysozyme adsorbed on BCP of adzuki bean on cooling at $25^{\circ} \mathrm{C}$ after heat treatment at $90^{\circ} \mathrm{C}$ for $30 \mathrm{~min}$. After heat treatment, the aqueous solution of lysozyme adsorbed on BCP of adzuki bean was incubated in a water bath thermostated at $25^{\circ} \mathrm{C}$. Overall concentrations of lysozyme and BCP were $33 \mu \mathrm{M}$ and $3 \mathrm{~g} / \mathrm{L}$, respectively. 


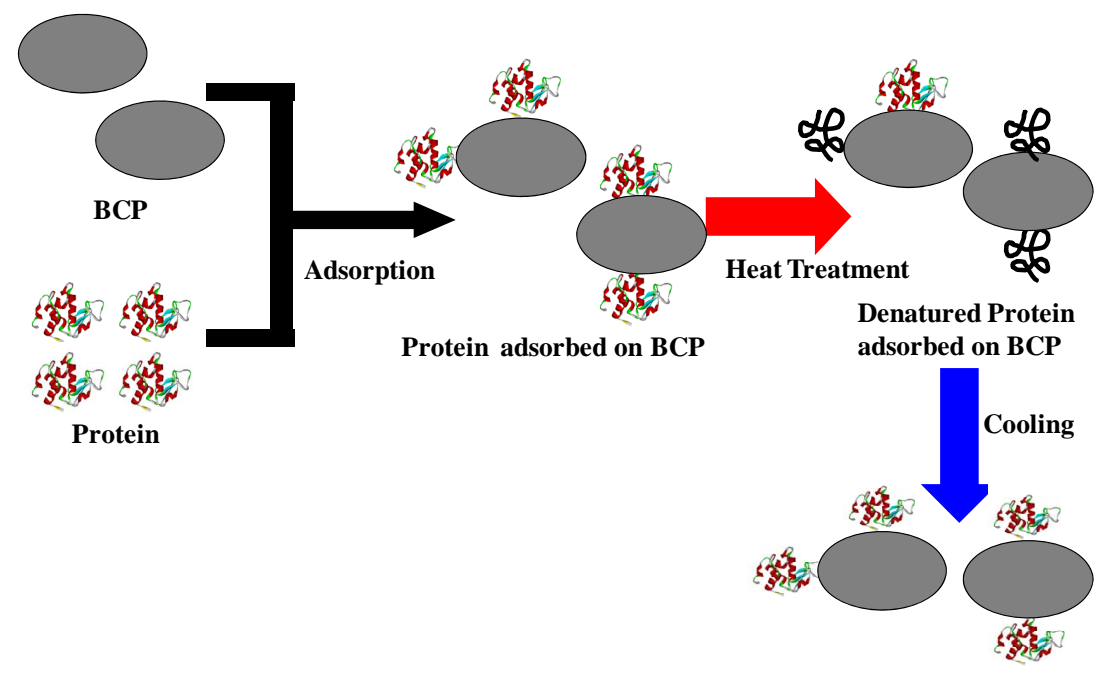

Refolded Protein adsorbed on BCP

Figure 6. Schematic representation of thermostabilization of proteins adsorbed on BCP.

temperatures of $90^{\circ} \mathrm{C}$ or higher. On the other hand, the remaining activity of lysozyme adsorbed on $\mathrm{BCP}$ of adzuki bean dropped in the range from $70^{\circ} \mathrm{C}$ to $98^{\circ} \mathrm{C}$, and still exhibited $3 \%$ at $98^{\circ} \mathrm{C}$. These results indicated that adsorbing lysozyme on BCP of adzuki bean effectively improved the thermal stability of lysozyme at high temperatures.

\subsection{Relationship between the Remaining Activity of Lysozyme Adsorbed on Biomass Charcoal Powder and the Kind of Biomass Charcoal Powder}

In order to extend our study, the remaining activities of lysozyme adsorbed on BCP prepared from different plant biomass wastes after heat treatment at $90^{\circ} \mathrm{C}$ for 30 min were investigated. Thermal stability of lysozyme was sufficiently enhanced by adsorbing lysozyme on BCP of bamboo or wood as well as the case of BCP of adzuki bean, as shown in Figure 8, while several percent of remaining activity was obtained by mixing lysozyme and BCP of bamboo or wood. The remaining activity of lysozyme adsorbed on BCP of adzuki bean was best among BCP examined in the present work. Amount adsorbed was almost same among three different materials, although the mean diameter of BCP of wood was 2.5 times larger than others, as seen in Table 1. On the other hand, as the water wettability of BCP of adzuki bean preferred to that of bamboo or wood, the dispersibility of $\mathrm{BCP}$ of adzuki bean in an aqueous solution was better than that of bamboo or wood.

\section{CONCLUSIONS}

We have demonstrated that the remaining activity of lysozyme adsorbed on BCP of adzuki bean is sufficiently

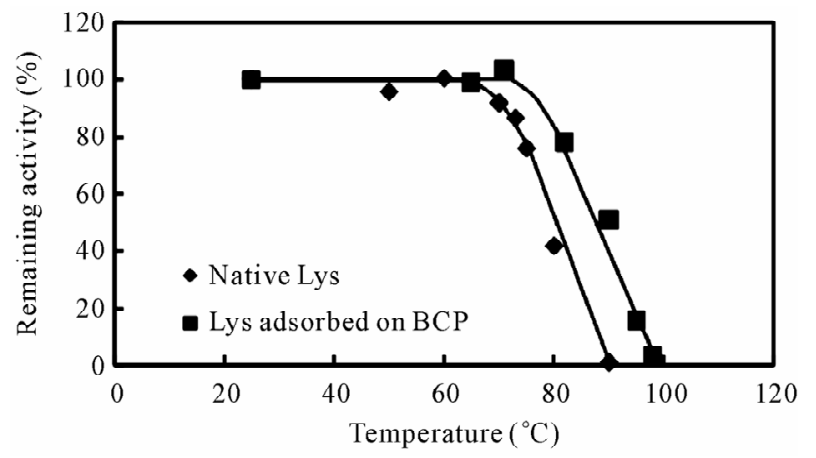

Figure 7. Thermal denaturation curves of native lysozyme and lysozyme adsorbed on BCP of adzuki bean. The aqueous solution of native lysozyme or lysozyme adsorbed on BCP of adzuki bean was incubated in a silicone oil bath thermostated at requisite temperature for $30 \mathrm{~min}$. Overall concentrations of lysozyme and BCP were $33 \mu \mathrm{M}$ and $3 \mathrm{~g} / \mathrm{L}$, respectively.

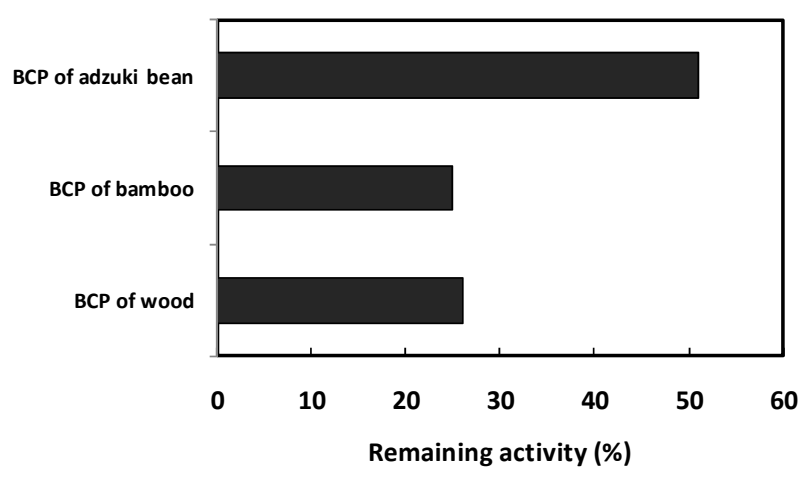

Figure 8. Effect of kind of BCP on remaining activity of lysozyme adsorbed on $\mathrm{BCP}$ after heat treatment at $90^{\circ} \mathrm{C}$ for 30 min. Overall concentrations of lysozyme corresponded to 33 $\mu \mathrm{M}$ on BCP of adzuki bean, $27 \mu \mathrm{M}$ on BCP of bamboo, and 36 $\mu \mathrm{M}$ on $\mathrm{BCP}$ of wood, respectively. Overall concentration of $\mathrm{BCP}$ was $3 \mathrm{~g} / \mathrm{L}$. 
Table 1. Mean diameter of BCP and amount of lysozyme adsorbed on BCP.

\begin{tabular}{ccc}
\hline Kind of BCP & Mean diameter $(\mu \mathrm{m})$ & Amount adsorbed $(\mu \mathrm{mol} / \mathrm{g})$ \\
\hline adzuki bean & 7 & 11 \\
bamboo & 7 & 9 \\
wood & 18 & 12 \\
\hline
\end{tabular}

maintained after heat treatment at high temperatures, compared to the case of native lysozyme, since adsorbing proteins on BCP hinders aggregation of thermally denatured proteins effectively, causes some of proteins to be intact at high temperatures, and enhances the refolding of thermally denatured proteins by cooling treatment. Regarding thermal stabilization effect of $\mathrm{BCP}$ on the remaining activity of adsorbed lysozyme after heat treatment, BCP of adzuki bean was much superior to BCP of bamboo or wood. The results obtained at the present work indicated that BCP had sufficient biocompatibility.

\section{ACKNOWLEDGEMENTS}

This work was supported by grants from Japan Science and Technology Agency (AS2111014D).

\section{REFERENCES}

[1] Volkin, D.B. and Klibanov, A.M. (1989) Minimizing protein inactivation. In: Creighton T.E. Ed., Protein function: Practical approach, IRL Press, Oxford, 1-24.

[2] Klibanov, A.M. (1983) Stabilization of enzymes against thermal inactivation. Advances in Applied Microbiology, 29, 1-28. doi:10.1016/S0065-2164(08)70352-6

[3] Gerlsma, S.Y. (1968) Reversible denaturation of ribonuclease in aqueous solutions as influenced by polyhydric alcohols and some other additives. Journal of Biological Chemistry, 243, 957-961.

[4] Kaushik, J. K. and Bhat, R. (1998) Thermal stability of proteins in aqueous polyol solutions: Role of the surface tension of water in the stabilizing effect of polyols. Journal of Physical Chemistry B, 102, 7058-7066. doi:10.1021/jp9811191

[5] Back, J.F., Oakenfull, D. and Smith, M.B. (1979) Increased thermal stability of proteins in the presence of sugars and polyols. Biochemistry, 18, 5191-5196. doi:10.1021/bi00590a025

[6] Lee, J.C. and Timasheff, S.N. (1981) The stabilization of proteins by sucrose. Journal of Biological Chemistry, 256, 7193-7201.

[7] Santoro, M.M., Liu, Y., Khan, S.M.A., Hou, L.-X. and Bolen, D.W. (1992) Increased thermal stability of proteins in the presence of naturally occurring osmolytes. Biochemistry, 31, 5278-5283. doi:10.1021/bi00138a006

[8] Yancey, P.H., Clark, M.E., Hand, S.C., Bowlus, R.D. and Somero, G.N. (1982) Living with water stress: Evolution of osmolyte systems. Science, 217, 1214-1222. doi:10.1126/science.7112124
[9] Arakawa, T., Bhat, R. and Timasheff, S.N. (1990) Why preferential hydration does not always stabilize the native structure of globular proteins. Biochemistry, 29, 19241931. doi:10.1021/bi00459a037

[10] Ikegaya, K. (2005) Kinetic analysis about the effects of neutral salts on the thermal stability of yeast alcohol dehydrogenase. Journal of Biochemistry, 137, 349. doi: $10.1093 / \mathrm{jb} / \mathrm{mvi} 037$

[11] Cioci, F. and Lavecchia, R. (1998) Thermostabilization of proteins by water-miscible additives. Chemical and Biochemical Engineering Quarterly, 12, 191-199.

[12] Noritomi, H., Minamisawa, K., Kamiya, R. and Kato, S. (2011) Thermal stability of proteins in the presence of aprotic ionic liquids. Journal of Biomedical Science and Engineering, 4, 94-99. doi:10.4236/jbise.2011.42013

[13] Illanes, A. (1999) Stability of biocatalysts. Electronic Journal of Biotechnology, 2, 1-9.

[14] Elnashar, M.M.M. (2010) Review article: Immobilized molecules using biomaterials and nanobiotechnology. Journal of Biomaterials and Nanobiotechnology, 1, 6177. doi:10.4236/jbnb.2010.11008

[15] Wang, J., Liu, J. and Cepra, G. (1997) Thermal stabilization of enzymes immobilized within carbon paste electrodes. Analytical Chemistry, 69, 3124-3127. doi:10.1021/ac9702305

[16] Asuri, P., Karajanagi, S.S., Vertegel, A.A., Dordick, J.S. and Kane, R.S. (2007) Enhanced stability of enzymes adsorbed onto nanoparticles. Journal of Nanoscience and Nanotechnology, 7, 1675-1678. doi:10.1166/jnn.2007.453

[17] Chaplin, M.F. and Bucke, C. (1990) Enzyme technology. Cambridge University Press, Cambridge.

[18] Gonzalez, M.T., Molina-Sabio, M. and Rodrigues-Reinoso, F. (1994) Steam-activation of olive stone chars. Development of porosity. Carbon, 32, 1407-1413. doi:10.1016/0008-6223(94)90133-3

[19] Lussier, M.G., Shull, J.C. and Miller, D.J. (1994) Activated carbon from cherry stones. Carbon, 32, 1493-1498. doi:10.1016/0008-6223(94)90144-9

[20] Noszko, L.H., Bota, A., Simay, A. and Nagy, L.G. (1984) Preparation of activated carbon from the by-products of agricultural industry. Periodica Polytechnica, 28, 293297.

[21] Rivera-Utrilla, J., Ultera-Hidalgo, E., Ferro-Garcia, M.A. and Mereno-Castilla, C. (1991) Comparison of activated carbons prepared from agricultural raw materials and Spanish lignites when removing chlorophenols from aqueous solution. Carbon, 29, 613-619. doi:10.1016/0008-6223(91)90128-6

[22] Rodrigez-Reinoso, F. and Molina-Sabio, M. (1992) Activated carbons from lignocellulosic materials by chemical and/or physical activation: An overview. Carbon, 30, 1111-1118. doi:10.1016/0008-6223(92)90143-K

[23] Jollès, P. (1996) Lysozymes: Model enzymes in biochemistry and biology. Birkhäuser Verlag, Basel.

[24] Ahern, T.J. and Klibanov, A.M. (1985) The mechanism of irreversible enzyme inactivation at $100^{\circ} \mathrm{C}$. Science, 228, 1280-1284. doi:10.1126/science. 4001942

[25] Nohara, D., Mizutani, A. and Sakai, T. (1999) Kinetic study on thermal denaturation of hen egg-white lysozyme involving precipitation. Journal of Bioscience and Bioengineering, 87, 199-205. 
doi:10.1016/S1389-1723(99)89013-6

[26] Lumry, R. and Eyring, H. (1954) Conformation changes of proteins. Journal of Physical Chemistry, 58, 110-120. doi: $10.1021 / \mathrm{j} 150512 \mathrm{a} 005$

[27] Zale, S.E. and Klibanov, A.M. (1983) On the role of reversible denaturation (unfolding) in the irreversible thermal inactivation of enzymes. Biotechnology and Bioengineering, 25, 2221-2230. doi:10.1002/bit.260250908

[28] Ibara-Molero, B. and Sanchez-Ruiz, J.M. (1997) Are there equilibrium intermediate states in the urea-induced unfolding of hen egg-white lysozyme? Biochemistry, 36, 9616-9624. doi:10.1021/bi9703305

[29] Griko, Y.V., Freire, E., Privalov, G., Dael, H.V. and Privalov, P.L. (1995) The unfolding thermodynamics of c-type lysozyme-A calorimetric study of the heat denaturation of equine lysozyme. Journal of Molecular Biology, 252, 447-459. doi:10.1006/jmbi.1995.0510

[30] Privalov, P.L. and Khechinashvili, N.N. (1974) A thermodynamic approach to the problem of stabilization of globular protein structure. Journal of Molecular Biology, 86, 665-684. doi:10.1016/0022-2836(74)90188-0

[31] Khechinashvili, N.N., Privalov, P.L. and Tiktopulo, E.I. (1973) Calorimetric investigation of lysozyme thermal denaturation. FEBS Letters, 30, 57-60. doi:10.1016/0014-5793(73)80618-0

[32] Anfinsen, C.B. (1973) Principles that govern the folding of protein chains. Science, 181, 223-230. doi:10.1126/science.181.4096.223 